\title{
TISSUE REACTION TO THE NICKEL IMPLANTS IN THE GUINEA PIGS
}

\section{BEATA KRECISZ ${ }^{1}$, MARTA KIEĆ-ŚWIERCZYŃSKA ${ }^{1}$, JOANNA PIASECKA-ZELGA², DOROTA CHOMICZEWSKA-SKÓRA ${ }^{1}$, and JAN STETKIEWICZ ${ }^{3}$}

\author{
${ }^{1}$ Nofer Institute of Occupational Medicine, Łódź, Poland \\ Center of Occupational Allergy and Environmental Health \\ ${ }^{2}$ Nofer Institute of Occupational Medicine, Łódź, Poland \\ Research Laboratory of Medicine and Veterinary Products in the GMP Quality System \\ ${ }^{3}$ Nofer Institute of Occupational Medicine, Łódź, Poland \\ Department of Toxicology and Carcinogenesis
}

\begin{abstract}
Objectives: The aim of the study was the assessment of local tolerance to nickel implants during 9 months observation in guinea pigs sensitized to nickel before implantation and non-sensitized ones. Materials and Methods: Three groups of guinea pigs were included in the study: 10 sensitized to nickel by the guinea pig maximization test; 10 previously nonsensitized and 10 in control group. In 20 animals (except control group) the nickel implants were inserted in the muscle of the back. After 9 months of observation, the animals were patch-tested with 5\% nickel sulfate. Also percentage of eosinophils in peripheral blood was examined. Next, the tissue surrounding the implant and skin from the area of patch tests were collected for the histological examination. Results: In $70 \%$ of previously sensitized animals, the patch test confirmed the sensitivity to nickel. In $60 \%$ of previously non-sensitized animals, a positive reaction to nickel occurred. The results of patch tests in control group were negative. Percentage of eosinophils in peripheral blood was fourfold higher in animals sensitized to nickel than in control group. In histological examination, in the tissue surrounding the implant a dissimilarity concerning the intensity of cellular infiltration was observed between animals previously allergic and non-allergic to nickel. In the 2 of 10 previously sensitized guinea pigs quite severe inflammatory reactions in the inside of connective tissue capsule were noted which may indicate a local allergic reaction. The histological images of skin collected from the positive patch test site corresponded with the typical allergic contact dermatitis. Conclusions: Nickel implants may cause primary sensitization to nickel. The nature of the histological changes in the tissues around the implants in guinea pigs sensitized to nickel may correspond to an allergic reaction. The examination of percentage of eosinophils in blood of guinea pigs may be useful in assessing the allergenic activity of metal alloys containing nickel.
\end{abstract}

Key words:

Nickel implants, Contact allergy, Guinea pigs

\footnotetext{
The study was conducted in 2009 and 2010 as part of the realization of the Nofer Institute of Occupational Medicine project entitled "Experimental assessment of local tolerance of nickel implants in guinea-pigs sensitized and non-sensitized to nickel", financed with the resources granted by the Ministry of Science and Higher Education. The subject manager: Beata Kręcisz, MD, PhD.

Received: January 9, 2012. Accepted: April 3, 2012.

Adress reprint requests to B. Kręcisz, Nofer Institute of Occupational Medicine, św. Teresy 8, 91-348 Łódź, Poland (e-mail: krecisz@imp.lodz.pl).
} 


\section{INTRODUCTION}

There is a constantly growing number of operations including metal implants. It has been estimated that approximately $5 \%$ of patients are afflicted by post-operation complications, e.g. chronic inflammation, pain, loosening of joint prostheses [1]. Consequently, the significance of contact allergy to metals as the cause of the rejection of implants is the subject of discussion among many researchers. Some authors indicate that, despite the presence of metal allergy, the implanted material is often well tolerated [2]. On the other hand, up to $21 \%$ of patients with preoperative metal sensitivity may develop cutaneous allergic reactions upon reexposure to the same metal [3]. Causative agents are usually nickel, cobalt and chromium, which are present in many metal alloys used in medical devices [4,5].

The aim of the study was the assessment of local tolerance to nickel implants in guinea pigs sensitized to nickel before implantation and non-sensitized ones.

\section{MATERIALS AND METHODS}

Thirty guinea pigs Imp: DH, divided into 3 groups, were used in the study:

- Group I - 10 guinea pigs sensitized to nickel by the guinea pig maximization test (GPMT) of the Magnusson and Kligman method [6],

- Group II - 10 guinea pigs previously non-sensitized,

- Control group - 10 guinea pigs.

All animals used in the experiment were 3 months old, weighing 450-500 g.

In the animals of I and II group, the nickel implants were inserted in the muscle of the back. The implantation procedure was carried out in accordance with the relevant Polish and European standards [7,8].

The guinea pigs were numbed with inhaled anesthesia halothane $\sim 2.0 \% \mathrm{v} / \mathrm{v}$. The fur from the area of the back was removed by shaving it with electric razor, then the shaved spot was wiped with antiseptic solution of iodine.

Next, the skin was incised at the length of $4 \mathrm{~mm}$ and the implant (size $10 \times 2 \times 1 \mathrm{~mm}$ ) was inserted into the muscle tissue. After the procedure, the tunnel was sewed with surgical thread.

The guinea pigs from the control group were treated with the same procedure, apart from the insertion of the implant. Thus, a "fake" implantation procedure was carried out.

Animals were placed in separate cages and were subjects of a 9 month long observation. During that period, every month, a general health and behavior assessment, measurement of the body weight and the examination of the skin (with particular attention to the post-procedure scar and skin above the implant) were performed. The results were noted in the individual animal's assessment cards.

After 9 months of observation period, every guinea pig was shaved on the side of its body, and after 24 hours the challenge patch tests with $5 \%$ nickel sulfate in petrolatum using IQ Chambers (Chemotechnique Diagnostics, Vellinge, Sweden) were applied. The readings were made two and three days after the test application. The results were evaluated according to the scale: 0 - no visible reaction; +- discrete or patchy erythema; ++- moderate and confluent erythema; +++ - erythema and swelling [6]. From every animal $2 \mathrm{ml}$ of blood was collected and placed in a test tube containing anticoagulant EDTA (ethylenediaminetetraacetate) from KABE-Labortechnik $\mathrm{GmbH}$ Nümbrecht-Elsenroth, Germany in order to determine the percentage of eosinophils and basophils in peripheral blood.

Afterwards, the animals were euthanized by the overdose of the $18 \%$ pentobarbital sodium at a dose of $200 \mathrm{mg} / \mathrm{kg}$ by intraperitoneal injection.

All animals from I and II group, after cross-cutting the skin in the midline posterior and localizing the implant, were subjected to macroscopic assessment of the tissue 
surrounding the implant. Next, the tissue surrounding the implant was removed for the histological examination.

The same procedure was carried out in the animals of the control group.

The tissue material for histological examinations was fixed by $10 \%$ formaldehyde solution in phosphate buffer and processed by routine paraffin technique in an automatic tissue processor. Then the specimens were sectioned to a thickness of 4-6 $\mu \mathrm{m}$, mounted on common glass slides and stained with haematoxylin and eosin according to standard procedures.

\section{Statistical methods}

Parameter differences between groups were tested using the Mann-Whitney $U$ test. Within group relationships were assessed using Spearman correlation coefficient. Two-sided tests were used with a significance level of $p=0.05$. Statistical analysis of the results was performed with the software Statistica 8.

\section{ETHICS}

This study protocol was approved by the Animal Ethics Committee No 9 in Łódź, Poland (Decision No 19/ LB 459/2009). All guinea pigs were kept under standard animal housing conditions, with food and water accessible ad libitum.

\section{RESULTS}

During the 9 months observation the animals' general health state was good and did not differ among individual groups. The postoperative wounds were healed, and the scar was observed.

The local (area above the implant) or generalized skin lesions were not observed in any of the guinea pigs from I, II or control group.

\section{The results of patch tests with $5 \%$ nickel sulfate} after 9 month period of observation

Group I (previously sensitized to nickel) In 7 out of 10 animals (70\%) the patch test confirmed the sensitivity to nickel (in 3 animals the reaction was assessed at ++ , in 4 animals at +++ ). No exacerbation of the reaction in particular animals was observed after 9 month period of the exposure to nickel implant. In 3 other animals the results of patch tests were negative.

Group II (previously non-sensitized to nickel)

In 6 out of $10(60 \%)$ animals a positive reaction occurred (in 4 animals the reaction were assessed at ++ , and in 2 animals at +++ ). In the 4 other guinea pigs the tests were negative.

\section{Control group}

The results of patch tests in all animals were negative.

\section{The results of blood examination}

\section{after 9 month period of observation}

Determination of percentage

of eosinophils in peripheral blood

The mean value was $9.21 \pm 6.52$ for group I, $7.94 \pm 5.82$ for group II, while for control group it was $2.01 \pm 0.72$. The percentage of eosinophils was significantly higher in group II than in the control group ( $p=0.004)$; a significant difference was also noted in group I compared to the control group $(p=0.049)$.

The results of determinations of eosinophils in particular animals are shown in Figure 1. The range of normal values of eosinophils in peripheral blood of guinea pigs was from $1 \%$ to $5 \%$ [9].

The correlation coefficient ( $r h o=0,74 ; \mathrm{p}=0.014$ ) indicated a strong correlation between the positive patch test results and the percentage of eosinophils in peripheral blood in guinea pigs in group II and no correlation in group I (rho $=-0.11 ; \mathrm{p}=0.76$ ). 


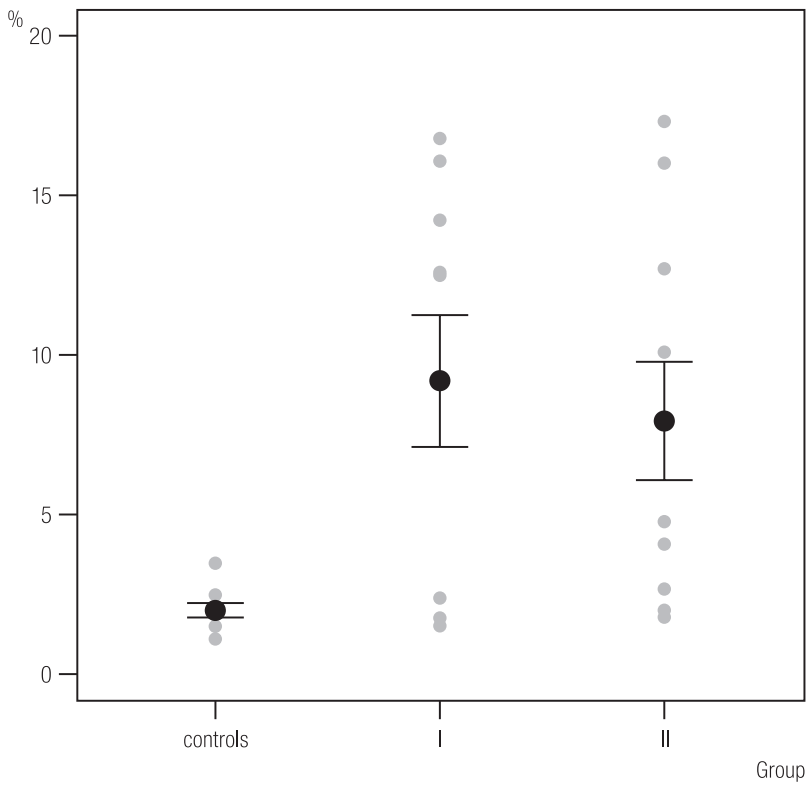

Fig. 1. Percentages of eosinophils in peripheral blood in particular guinea pigs after 9 months since implantation of nickel implants

The results of percentage of basophils in peripheral blood

In groups I and II, the percentage of basophiles was within normal limits. Mean values of basophiles were $0.4 \pm 0.13,0.3 \pm 0.19$ and $0.4 \pm 0.19$ in control, I and II group, respectively. Statistical analysis did not show any significant difference between examined and control groups. The range of normal values for guinea pigs is from 0.3 to $0.8 \%$ [9].

The correlation coefficient for group I (rho $=-0.04$; $\mathrm{p}=0.91)$ and group II (rho $=0.54 ; \mathrm{p}=0.11)$ indicated no correlation between the positive patch tests results and the percentage of basophils in peripheral blood in guinea pigs.

\section{The results of histological examination}

\section{Group I (previously sensitized to nickel)}

Nickel implants were located among the back muscles or under the epimysium. They were surrounded by connective tissue capsule of ca. 10-40 $\mu$ m thickness. In the 2 of 10 guinea pigs the capsules after removing the implant were partially filled with exudate comprising lymphoid cells, plasmocytes and sparse macrophages and granulocytes. Minimal infiltration comprising sparse lymphocytes, plasmocytes and histiocytes were encapsulated by the neighbouring tissues. No detectable changes were seen in the back muscles.

Ninety six hrs after challenge patch test with 5\% nickel sulfate, morphological changes were noted in skin in the 7 of $10(70 \%)$ previously sensitized guinea pigs. The epidermis was 2-3-fold increased with hyperkeratosis, focal granulosis and acanthosis. Local vacuolisation of the basal cell was observed. In the dermis, fairly extensive infiltrations of lymphoid cells, plasmocytes and histiocytes were located close to epidermis. There was an increase in thickness of the dermis arteries. In their surroundings, a number of the lymphoid cells were noted.

\section{Group II (previously non- sensitized to nickel)}

Nickel implants were located among the back muscles or under the epimysium. They were surrounded by connective tissue capsule of ca. 10-35 $\mu \mathrm{m}$ thickness. Minimal infiltrations consisting of sparse lymphocytes, plasmocytes and histiocytes were noted in the surrounding capsule tissues. No detectable changes were seen in the back muscles. Ninety six hrs after challenge patch test with 5\% nickel sulfate, morphological changes were noted in skin in the 6 of $10(60 \%)$ guinea pigs, i.e. in all animals with positive patch test reaction. The epidermis was $2-3$ fold increased, with hyperkeratosis, focal granulosis and moderate acanthosis. Local vacuolisation of the basal cells was observed. Signs of proliferation of the epithelium of hair follicles were also noted. In the dermis, scattered mononuclear cell infiltrations were located close to epidermis (Photo 1).

\section{Control group}

In control animals no significant changes were noted in the epidermis, dermis, skin appendices or muscles (Photo 2). 


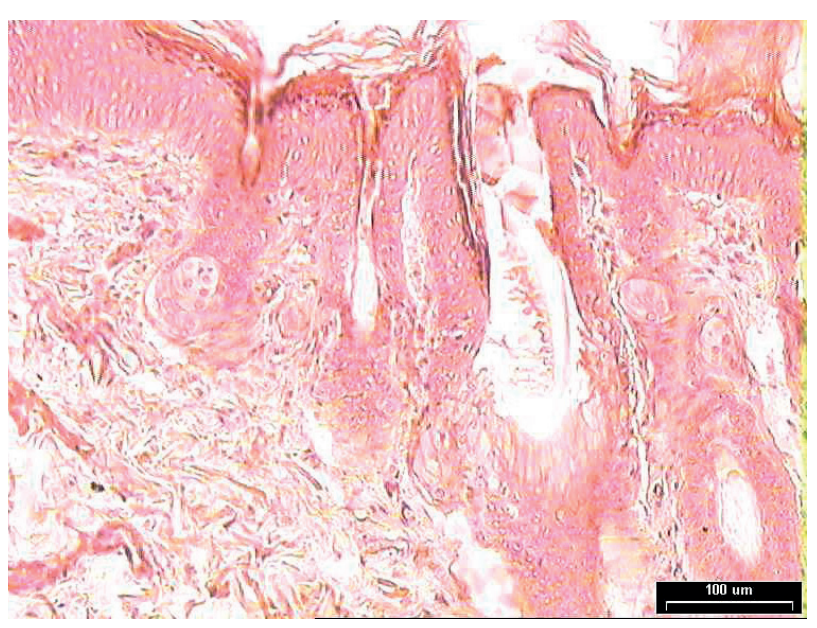

There is thickening of the granulosa layer, and acanthosis with intracellular oedema. The upper dermis shows moderate mononuclear infiltrate invading the basal layer of the dermis.

Photo 1. Histological examination of positive patch test result with 5\% nickel sulfate in guinea pig with nickel implant held for 9-month period

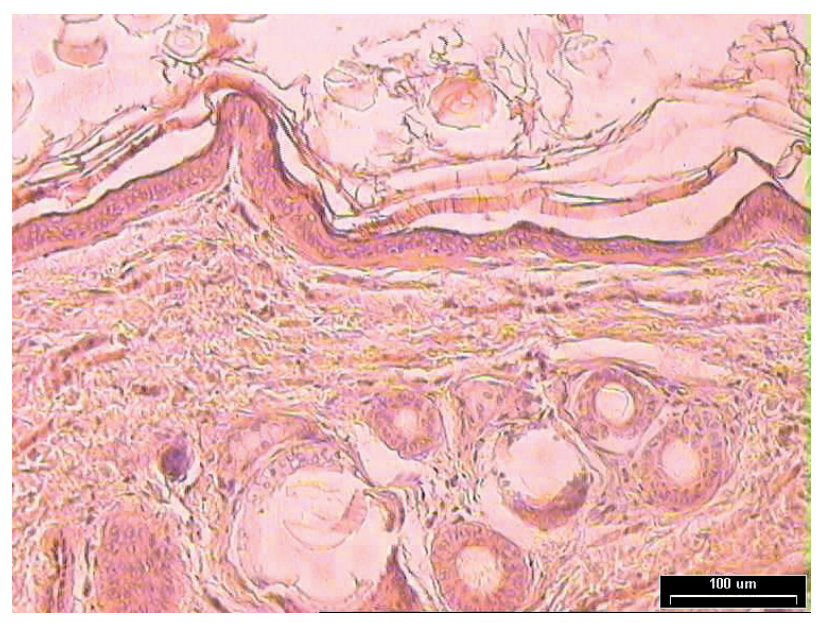

The epidermis and dermis appear to be within normal limits. $\mathrm{H} \&$ E staining.

Photo 2. Histological examination of negative patch test result with $5 \%$ nickel sulfate in guinea pig from control group

\section{DISCUSSION}

Nickel is commonly known for being a contact allergen causing an allergy when the skin is in chronic contact with metal objects containing it [10]. Nevertheless, association between metal allergy and device failure is disputable $[2,3,11,12]$. Also studies conducted with the involvement of animals were inconclusive. Differences in tissue reactions to nickel screws in nickel-sensitive and in non-sensitive animals were reported by Merritt et al. [13]. On the other hand, Lewin et al. [14] showed the absence of local response to bone screws in guinea pigs with contact sensitivity. The results of our study conducted with the involvement of guinea pigs (which are recommended for studying contact allergy) [6,15], show that nickel released from the implants may evoke the primary sensitization.

In $60 \%$ of previously non-sensitized animals, positive patch tests with nickel sulfate after 9 months of implant usage were observed. Moreover, the histological images of skin taken from the test site corresponded with the typical contact dermatitis. In the tissue surrounding the implant a dissimilarity in the intensity of cellular infiltration was observed depending on whether the animal was previously allergic to nickel or if it was sensitized to nickel in the course of the study.

In the group of guinea pigs sensitized to nickel by the implant usage only, scattered infiltrations of lymphoid cells, histiocytes, and plasmatic cells having the character of the foreign body reaction, were observed.

However, in some animals that have been previously sensitized to nickel, a quite severe inflammatory reactions in the inside of the connective tissue capsule were noted, which may be indicative of a local allergic reaction.

These observations raise the question: why, in spite of the sensitization, there were no significant tissue reactions to implant in the group of animals sensitized by the implant? Perhaps the period of observation was too short. We do not know how much time after installing the implant was required by the guinea pigs to modify their immune system. On the other hand, in animals sensitized to nickel by GPMT method, the tissue allergic reactions might have developed much earlier.

Nevertheless, the studies have shown that in some sensitized animals (during the 9-month period of observation) a tissue reaction having a nature of an allergic reaction, 
that could be the cause of poor tolerance of implants, was observed.

In our opinion, particular attention should be paid to the correlation between the positive patch tests results to nickel and the increased concentration of blood eosinophils. The increase of blood eosoinophils is characteristic of provocation with the inhalant allergens, both in animals and humans [16,17] but, according to our knowledge, was not previously examined in animals while studying the contact allergy. In our experiment, 5 out of 6 animals sensitized by the implant showed an increase in the concentrations of blood eosoinophils.

It seems reasonable to consider the feasibility of using the determinations of this parameter in allergenic assessment of chemicals as an additional marker of contact allergy.

\section{CONCLUSIONS}

1. Nickel implants embedded in the muscle tissue may cause primary sensitization to nickel.

2. In the histological examination the nature of the changes in the tissues around the implants in nickelsensitized guinea pigs may correspond to an allergic reaction.

3. The determinations of percentage of eosinophils in blood of guinea pigs may be useful in assessing the allergenic activity of metal alloys containing nickel.

\section{REFERENCES}

1. Villar RN. Failed hip replacements. Br Med J 1992;304:3-4.

2. Carlsson A, Moller H. Implantation of orthopaedic devices in patients with metal allergy. Act Derm Venereol 1989;69:62-6.

3. Niki Y, Matsumoto H, Otani T, Yatabe T, Kondo M, Yoshimine F, et al. Screening for symptomatic metal sensitivity: a prospective study of 92 patients undergoing total knee arthroplasty. Biomaterials 2006;26:1019-26.
4. Basko-Plluska JL, Thyssen JP, Schalock PC. Cutaneous and systemic hypersensitivity reactions to metallic implants. Dermatitis 2011;22:65-79.

5. 316/316L stainless steel. Product data sheet [cited 2011 December 15]. Available on URL: http://www.aksteel.com/ PDF/markets_products/stainless/austenitic/316_316L_ Data_Sheet.pdf.

6. Magnusson B, Kligman AM. The Identifications of contact allergens by animal assay. The guinea pig maximization test. J Invest Dermatol 1969;52:268-76.

7. Polish Standard PN-EN 30996-6. Biological evaluation of medical devices. Tests for local effects after implantation. Warszawa: Polish Committee for Standardization; 2000 [in Polish].

8. Biological evaluation of medical devices. Part 6: Tests for local effects after implantation. ISO 10993-6:1994. Arlington: Association for the Advancement of Medical Instrumentation; 2007.

9. Brylińska J, Kwiatkowska J, editors. Laboratory animals methods of farming and experiments. Kraków: Towarzystwo Autorów i Wydawców Prac Naukowych Uniwersitatis; 1996 [in Polish].

10. Thyssen JP, Linneberg A, Menné T, Duus Johansen J. The epidemiology of contact allergy in the general population - prevalence and main findings. Contact Dermatitis 2007;57:287-99.

11. Basko-Pluska, JL, Thyssen JP, Schalock PC. Cutaneous and systemic hypersensitivity reactions to metallic implant - an update. Dermatitis 2011;22:65-79.

12. Schalock PC, Menné T, Johansen JD, Taylor JS, Maibach HI, Lidén $\mathrm{K}$, et al. Hypersensitivity reactions to metallic implants diagnostic algorithm and suggested patch test series for clinical use. Contact Dermatitis 2012;66:4-19.

13. Merritt K, Brown SA. Tissue reaction and metal sensitivity. An animal study. Acta Orthop Scand 1980;51:403-11.

14. Lewin J, Lindgren JU, Wahlberg JE. Apparent absence of local response to bone screws in guinea pigs with contact sensitivity. J Orthop Res 1987;5:604-8.

15. Basketter DA, Andersen KE, Linden K, Van Lovergen H, Boman A, Bimber I, et al. Evaluation of the skin sensitizing 
potency of chemicals by using the existing methods and considerations of relevance for elicitation. Contact Dermatitis $2005 ; 52: 39-43$.

16. Tomaki M, Zhao LL, Lundahl J, Sjöstrand M, Jordana M, Lindén A, et al. Eosinophilopoiesis in a murine model of allergic airway eosinophilia: involvement of bone marrow IL-5 and IL-5 receptor $\alpha$. J Immunol 2000;165:4040-50.

17. Skrindo I, Scheel C, Johansen FE, Jahnsen FL. Experimentally induced accumulation of Foxp $3+T$ cells in upper airway allergy. Clin Exp Allergy 2011;41(7):954-62.

This work is available in Open Access model and licensed under a Creative Commons Attribution-NonCommercial 3.0 Poland License - http://creativecommons.org/ licenses/by-nc/3.0/pl/deed.en. 